\title{
Enantio- and regioselective CpRu-catalyzed Carroll rearrangement*
}

\author{
Martina Austeri, Frederic Buron, Samuel Constant, Jerome Lacour ${ }^{\ddagger}$, \\ David Linder, Jessica Müller, and Simone Tortoioli
}

\begin{abstract}
Department of Organic Chemistry, University of Geneva, quai Ernest Ansermet 30, $\mathrm{CH}-1211$ Geneva 4, Switzerland
\end{abstract}

\begin{abstract}
The addition of unstabilized carbonyl nucleophiles to allyl-metal fragments still represents a challenge for generating stereoselectively tertiary (and quaternary) stereogenic centers. In this context, the decarboxylative Carroll rearrangement of secondary and tertiary allyl $\beta$-ketoesters is particularly interesting since chiral $\gamma, \delta$-unsaturated ketones are obtained. Herein, we show that $\mathrm{CpRu}$ half-sandwich complexes can, in the presence of selected enantiopure diimine ligands, catalyze this transformation and afford complete conversions and decent level of enantiomeric excess. Zwitterionic adducts of a hexacoordinated phosphorus anion and $\mathrm{CpRu}$ moieties were also associated and shown to generate air-, moisture-, and microwave-stable catalysts that can be readily purified and recycled. Carroll rearrangements of allylic $\beta$-ketoesters performed with these zwitterionic species occur with better regio- and enantioselectivity.
\end{abstract}

Keywords: allyl complexes; enantioselective catalysis; ruthenium; N ligands; hexacoordinated phosphorus.

\section{INTRODUCTION}

Among the wide variety of synthetic methods allowing the construction of complex molecular structures, one of the most documented is the attack of a nucleophile onto an allyl-metal fragment yielding chiral allylic compounds in (virtually) enantiopure form. One of the benefits of such substitution is that the regioselectivity of the reaction onto unsymmetrical allyl substrates can be controlled by the metal catalyst [1]. In this respect, several ruthenium derivatives have proven to be largely effective for the introduction of nucleophiles at the more substituted position leading to branched (b) rather than linear (1) products (eq. 1) and $\mathrm{Cp} * \mathrm{Ru}$ derivatives in particular [2].

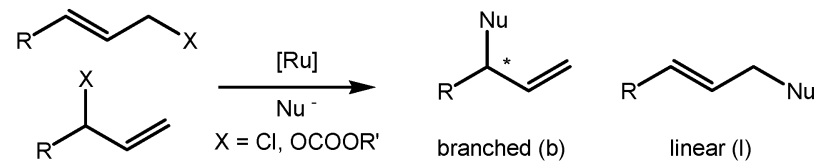

These include, among others, the tris(acetonitrile) complex $\left[\mathrm{Cp} * \mathrm{Ru}\left(\mathrm{CH}_{3} \mathrm{CN}\right)_{3}\right]\left[\mathrm{PF}_{6}\right] \mathbf{1 a}$ from Trost et al. [3], DAB and 2,2'-bipyridine (bpy) complexes of Bruneau, Demerseman, Renaud, and coworkers (2a and 3a) [4], 1,5-COD complexes of Kondo, Mitsudo et al. [5], amidinate of Nagashima

\footnotetext{
*Paper based on a presentation at the $14^{\text {th }}$ International Symposium on Organometallic Chemistry Directed Towards Organic Synthesis (OMCOS-14), 2-6 August 2007, Nara, Japan. Other presentations are published in this issue, pp. 807-1194.

¥Corresponding author: Fax: +41 (0)22 379 3215; E-mail: jerome.lacour@ chiorg.unige.ch
} 
et al. [6], and $\mathrm{Ru}^{\mathrm{IV}}$ carbonate derivatives from Pregosin et al. [7]. Very recently, this field of chemistry was comprehensively reviewed by Bruneau, Renaud, and Demerseman [2]. An extended introduction is, therefore, unnecessary.
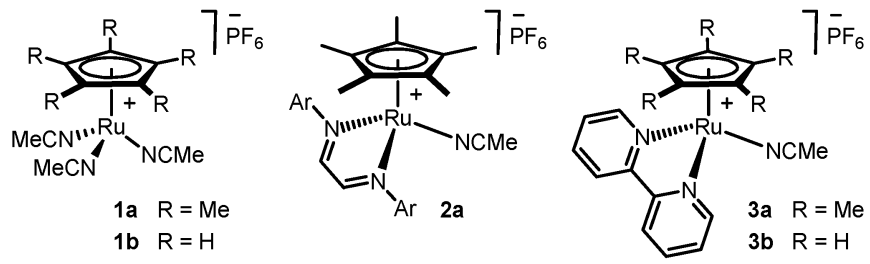

Typical substrates are allyl carbonates and allyl chlorides (primary or secondary) and effective allylic alkylation, arylation, amination, and etherification reactions have been developed [3-7]. If nonracemic secondary allyl carbonates are used, the reactions proceed stereospecifically with possibly complete transfer of chirality [3]. Cp*Ru derivatives are largely preferred over $\mathrm{CpRu}$ moieties (e.g., 1a over $\left.\left[\mathrm{CpRu}\left(\mathrm{CH}_{3} \mathrm{CN}\right)_{3}\right]\left[\mathrm{PF}_{6}\right](\mathbf{1 b}) ; \mathrm{Cp}=\mathrm{C}_{5} \mathrm{H}_{5}\right)$ as the more electron-rich metal fragment is catalytically more active and leads to higher $\mathrm{b} / \mathrm{l}$ ratios. Recently, an intramolecular variant of the allylic alkylation was described in the context of regioselective (and stereospecific) Carroll-type rearrangements [8]. Allyl- $\beta$-ketoesters of type 4 (eq. 2) were shown to react smoothly in the presence of [Cp*RuCl$]_{4} \mathbf{~} \mathbf{c}$ and bpy to form $\gamma, \delta$-unsaturated ketones (5) in high yields and excellent b/l ratios [8a]. The conditions were particularly mild $\left(\mathrm{CH}_{2} \mathrm{Cl}_{2}\right.$, rt). This is in sharp contrast with that of classical (thermal) decarboxylative $[3,3]$-sigmatropic Carroll reactions that require elevated temperatures to proceed (typically $140-180{ }^{\circ} \mathrm{C}$ ) [9]; the Carroll rearrangement being nevertheless a highly useful concerted reaction used for a variety of synthetic applications [10,11].

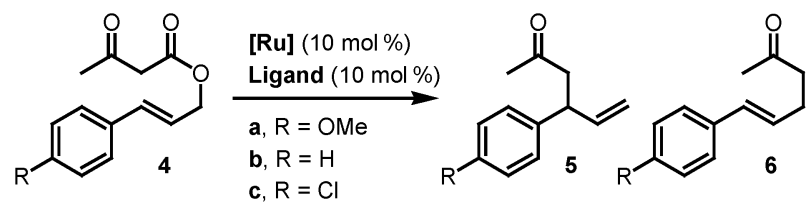

Despite all these advantages, Ru-catalyzed enantioselective allylic substitutions are rare $[12,13]$. To our knowledge, the etherification of allyl chlorides with phenols using, as catalyst, combinations of Cp*Ru 1a and box-type ligands (e.g., 7; Scheme 1) was the single-reported example of enantioselective Ru-catalyzed allylic substitution reaction onto unsymmetrical substrates prior to our own studies. Good enantioselectivity (ee up to $82 \%$ ) and decent regioselectivity (dr 1.6/1 to 6.5/1) were achieved [14]. This relative lack of enantioselective transformations led us to study asymmetric Ru-catalyzed $\mathrm{C}-\mathrm{C}$ bond-forming allylic substitution reactions and the Carroll reaction in particular. Our progress toward this goal is summarized in the following paragraphs. 

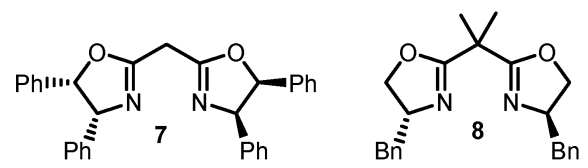<smiles>CC[C@H](/N=C/c1ccccn1)c1ccccc1</smiles><smiles>CC[C@H](/N=C/c1cc(N(C)C)ccn1)c1ccccc1</smiles><smiles>CC[C@H](/N=C/c1cccc([N+](=O)[O-])n1)c1ccccc1</smiles><smiles>CCC[C@H](N=Cc1ccccn1)c1ccccc1OC</smiles><smiles>C(=N/C(Cc1ccccc1)c1ccccc1)\c1ccccn1</smiles><smiles>CC(C)(C)[C@H](/N=C/c1ccccn1)c1ccccc1</smiles>

Scheme 1 (Chiral) diimine ligands.

\section{ENANTIO- AND REGIOSELECTIVE CpRu-CATALYZED CARROLL REARRANGEMENT}

In view of the previously mentioned results, initial experiments on the enantioselective Ru-catalyzed variant of the Carroll rearrangement were conducted by the treatment of allylic ester $\mathbf{4 a}$ (eq. $2, \mathrm{R}=$ $\mathrm{OMe}$ ) with catalytic amounts of $\mathbf{1 c}\left(2.5 \mathrm{~mol} \%\right.$ of the tetramer) and box ligand $\mathbf{8}(10 \mathrm{~mol} \%)$ in $\mathrm{CH}_{2} \mathrm{Cl}_{2}$ at room temperature. Unlike the reaction performed in the presence of bpy (15 min., $100 \%$ conv.), poor reactivity was observed in the presence of this bisoxazoline ligand ( $15 \%$ conv. after 7 days); no enantioselectivity being furthermore achieved (ee $0 \%$ ).

Obviously, ligand $\mathbf{8}$ did not possess the (stereo)electronic requirements for the activation of the ruthenium catalyst. To recover some reactivity, the presence of a pyridine moiety within the framework of the chiral diimine ligand was deemed necessary. Ligand 9a, readily synthesized by the condensation of 2-pyridine-carboxaldehyde and $(R)$-1-phenyl-propylamine, was prepared and submitted to the reaction conditions. Although very modest, the result was better (45\% conv. after 5 days, ee $13 \%$ ) than that of ligand 8. Intensive screening of solvent, temperature, concentration, and metal source (1) and 1c) then afforded effective conditions for the "Carroll" rearrangement; a combination of CpRu complex $\mathbf{1 b}$ and ligand 9a (10 mol \% each) in THF at $60{ }^{\circ} \mathrm{C}$, allowing the reaction to proceed with good yield and a first decent enantioselectivity (5a: ee $56 \%, 20 \mathrm{~h}, 100 \%$ conv., $95 \%$ yield) [15]. Significantly, no trace of the linear product (6a) was found using the Cp ruthenium catalyst $\mathbf{1 b}$ (NMR and GC/MS monitoring). The occurrence of a perfect branched-to-linear (b:l) ratio under the optimized conditions was confirmed in reactions performed with bpy and achiral iminopyridine ligand $\mathbf{9 b}$ (Scheme 1). The results are summarized in Table 1. 
Table 1 Ru-catalyzed rearrangement of allylic esters $4 .^{\mathrm{a}}$

\begin{tabular}{lcccccc}
\hline Ester & Ligand & Time & Conv. & ee & Conf. $^{\text {b }}$ & B:1 ratio \\
\hline $\mathbf{4 a}$ & - & $48 \mathrm{~h}$ & $0 \%$ & - & - & - \\
$\mathbf{4 a}$ & $\mathbf{9 a}$ & $20 \mathrm{~h}$ & $100 \% \mathrm{~d}$ & 56 & $(+)$ & $>99: 1$ \\
$\mathbf{4 a}$ & Bpy & $4 \mathrm{~h}$ & $100 \%$ & - & - & $>99: 1$ \\
$\mathbf{4 a}$ & $\mathbf{9 b}$ & $30 \mathrm{~h}$ & $100 \%$ & - & - & $>99: 1$ \\
$\mathbf{4 a}$ & $\mathbf{9 c}$ & $13 \mathrm{~h}$ & $97 \%$ & 50 & $(+)$ & $>99: 1$ \\
$\mathbf{4 a}$ & $\mathbf{9 d}$ & $92 \mathrm{~h}$ & $47 \%$ & 20 & $(+)$ & $>99: 1$ \\
$\mathbf{4 a}$ & $\mathbf{9 e}$ & $24 \mathrm{~h}$ & $100 \%$ & 58 & $(+)$ & $>99: 1$ \\
$\mathbf{4 a}$ & $\mathbf{9 f}$ & $22 \mathrm{~h}$ & $100 \%$ & 66 & $(+)$ & $>99: 1$ \\
$\mathbf{4 a}$ & $\mathbf{9 g}$ & $20 \mathrm{~h}$ & $100 \%$ & 72 & $(+)$ & $>99: 1$ \\
$\mathbf{4 a}$ & $\mathbf{9 h}$ & $24 \mathrm{~h}$ & $100 \%$ & 80 & $(+)$ & $>99: 1$ \\
$\mathbf{4 b}$ & $\mathbf{9 h}$ & $24 \mathrm{~h}$ & $100 \%$ & 74 & $(+)-(S)$ & $94: 6$ \\
$\mathbf{4 c}$ & $\mathbf{9 h}$ & $5 \mathrm{~d}$ & $75 \%$ & 66 & $(+)$ & $95: 5$ \\
\hline
\end{tabular}

${ }^{\mathrm{a}} \mathbf{1 b}(10 \mathrm{~mol} \%)$, ligand $(10 \mathrm{~mol} \%)$, THF, $60{ }^{\circ} \mathrm{C}, c 0.5 \mathrm{M}$; the results being the average of at least two runs;

bign of the optical rotation and absolute configuration when known;

${ }^{\mathrm{c}}$ Ratios of branched (5) to linear (6) were determined at complete conversion; $\mathrm{d}_{95} \%$ isolated yield.

At that stage, a rather intensive screening of chiral ligands was performed; a selection is presented in Scheme 1. To begin, the nature of the pyridine moiety was varied as substituents were introduced on the aromatic nucleus (9c: $p-\mathrm{NMe}_{2}, 9 \mathrm{~d}$ : $o$-Me). Whereas the dimethylamino substituent enhanced the reactivity of the catalyst, the presence of the methyl group at proximity of the coordinating nitrogen atom decreased strongly the reactivity; both modifications being at the expense of the ee. A series of chiral ligands (9e to $9 \mathbf{h}$ ) was then prepared by condensation of 2-pyridine-carboxaldehyde and other chiral benzylic primary amines [16]. From $9 \mathbf{e}$ to $9 \mathrm{~g}$, a gradual increase in the enantioselectivity of the allylic substitution was noticed (ee up to $72 \%$ ), which is most probably related to the increase in size of the benzylic $\alpha$-substituent [from Et (9a) to $\operatorname{Pr}, \mathrm{Bn}$ and then $t$-Bu]. Finally, a useful level of enantioselectivity was obtained (ee $80 \%$ ) when the reaction was performed in the presence ligand $9 \mathrm{~h}$ prepared from (R)-1-(2-methoxyphenyl)-2,2-dimethylpropan-1-amine [17,18]. Importantly, in all these examples, the b:1 ratio remained excellent with the Cp catalyst as no trace of compound $6 \mathbf{6}$ could be observed.

With that result in hand, the asymmetric protocol was extended to allylic esters $\mathbf{4 b}$ and $\mathbf{4 c}$ (eq. 2, $\mathrm{R}=\mathrm{H}$ and $\mathrm{Cl}$, respectively). The reaction with unsubstituted $\mathbf{4 b}$ proceeded somewhat less selectively in terms of enantio- and regiochemistry (ee $74 \%$ and b:1 94:6). With ligand $\mathbf{9 h},(+)-5 \mathbf{b}$ was obtained of which a $S$ configuration could be determined by hydrogenation to produce $(S)$-(2)-4-phenyl-2-hexanone [8b,19]. With $\mathbf{4 c}$ bearing a chlorine atom, the reaction was much slower than with $\mathbf{4 a}$ and $\mathbf{4 b}$ as $\mathbf{5}$ days were necessary to reach a decent conversion $(75 \%)$; the regio- and enantioselectivity remaining strong (ee $66 \%$ and b:1 95:5). The effect of the electron-withdrawing atom on the reactivity being in line with the results of Bruneau and Tunge $[4,8 \mathrm{~b}]$.

To gain some insight into the nature of the asymmetric transformation and achieve possibly higher level of selectivity, care was taken to perform the asymmetric Carroll rearrangement on a enantioenriched secondary allyl ester to determine (i) if the reaction still occurred stereospecifically under our set of conditions and (ii) if chiral ligands could affect positively (or not) the subsequent selectivity. We selected compound 10b (Table 2) for our study as the configuration of both starting material and product are known. The $R$ and $S$ enantiomers were prepared by olefination of commercially available enantiopure styrene oxide using the protocol developed by Mioskowski et al. and then esterification with diketene (10b, $R$ and $S$, ee $>99 \%$, CSP-GC) [20]. 
Table 2 Ru-catalyzed rearrangement of secondary allylic ester 10b. ${ }^{\mathrm{a}}$

\begin{tabular}{lccccr} 
Ester & Ligand & Time & ee & Conf. & B:1 ratio \\
\hline$(S)-10 b$ & bpy & 2 & 48 & $(+)-(S)$ & $94: 6$ \\
$(S)-10 b$ & $9 b$ & 6 & 72 & $(+)-(S)$ & $94: 6$ \\
$(S)-10 b$ & $9 a$ & 10 & 84 & $(+)-(S)$ & $92: 8$ \\
$(S)-10 b$ & $9 h$ & 10 & 92 & $(+)-(S)$ & $93: 7$ \\
$(R)-10 b$ & bpy & 2 & 46 & $(-)-(R)$ & $93: 7$ \\
$(R)-10 b$ & $9 b$ & 6 & 72 & $(-)-(R)$ & $94: 6$ \\
$(R)-10 b$ & $9 a$ & 6 & 68 & $(-)-(R)$ & $94: 6$ \\
$(R)-10 b$ & $9 h$ & 6 & 70 & $(-)-(R)$ & $>99: 1$ \\
\hline
\end{tabular}

${ }^{\mathrm{a}} \mathrm{All}$ reactions reached complete conversion by the reported time. $\mathbf{1 b}$ $(10 \mathrm{~mol} \%)$, ligand $(10 \mathrm{~mol} \%)$, THF, $60{ }^{\circ} \mathrm{C}, c 0.5 \mathrm{M}$; the results being the average of at least two runs.

${ }^{\mathrm{b}}$ Sign of the optical rotation and absolute configuration.

${ }^{\mathrm{c}}$ Ratios of branched $(\mathbf{5 b})$ to linear $(\mathbf{6} \mathbf{b})$ were determined at complete conversion.

To begin, both enantiomers of $\mathbf{1 0 b}$ reacted faster than their linear analog $4 \mathbf{b}$ [7a]; all reactions being completed in less than $10 \mathrm{~h}$ in the presence of achiral (bpy, 9b) or chiral ligands $(\mathbf{9 a}, 9 \mathbf{9 h})$. The results are summarized in Table 2. First, as in the case of $\mathbf{4 b}$, non-negligible amounts of linear product $\mathbf{6 b}$ could be observed in most of these reactions; the ratios, from 93:7 to better than 99:1, remaining however in line with the result obtained with the linear ester. In all cases, the reactions were stereospecific and a net retention of configuration was observed as $(R)$ - and $(S)$-10b afforded $(R)$ - and $(S)$-5b , respectively.

Using achiral bpy as ligand, a rather strong loss of selectivity was observed in our case (ee 46-48 \%), something substantially different from that observed by Tunge on the same substrate and different reaction conditions (ee 83-87\%) [8b]. Interestingly, iminopyridine 9b (Scheme 1) led to a better conservation of chiral information (ee $72 \%)$. In the reactions performed with $(R)$ - and $(S)$-10b in the presence of chiral ligands, $\mathbf{9 a}$ and $\mathbf{9 h}$, a rather distinct behavior was noticed. In the case of $(S)$-10b, a "matched" diastereomeric effect was observed as the reaction was influenced positively by the chiral ligands; (+)-(S)-5b being isolated in much better enantiomeric purity (ee up to $92 \%$ ) than in the reaction performed with achiral $\mathbf{9 b}$ - something not so unanticipated in view of the tendency of ligands $9 \mathbf{a}$ and $9 \mathrm{~h}$ to favor the formation of the $(+)-(S)$ enantiomer starting from $4 \mathbf{b}$. However, more surprising was the overall lack of (mismatched) influence of the chiral ligands on the reaction with $(R)-\mathbf{1 0 b}$ as $(-)-(R)$ $\mathbf{5 b}$ was isolated with essentially the same enantiomeric purity as in the reaction performed with achiral $\mathbf{9 b}$; the origin of this difference and the fact that this enantiomer reacts faster than $(S)$-10b remaining unclear at this moment.

\section{IMPROVED AIR- AND MICROWAVE-STABLE RUTHENIUM CATALYSTS}

Although useful, these reactions were, however, performed with usually large amounts of ruthenium catalysts $(\sim 10 \mathrm{~mol} \%)$ and the active complexes are not recovered at the end of the reaction due to their sensitivity to moisture, oxygen, and isolation conditions. To the best of our knowledge, only Bruneau, Renaud, and coworkers have been able to perform multiple catalytic cycles by immobilizing a cationic 
$\mathrm{Cp} * \mathrm{Ru}$ catalyst into an ionic liquid phase [21]. Cyclopentadienyl Ru derivatives that would be (i) airinsensitive, (ii) easily synthesized and purified, (iii) catalytically active, and (iv) possibly recoverable and reusable were thus looked for, and they would be important novelties in this field [22].

Recently, a novel hexacoordinated phosphate anion, namely TRISPHAT-N 11, was also described and proven to be an efficient counterion and ligand altogether able to enter the first coordination sphere of metal complexes $[23,24]$. Furthermore, it was shown that the derived zwitterionic metal complexes possess interesting chromatographic, air, and moisture stability. The possibility that $\mathbf{1 1}$ would form a stable complex with the mixture of $\left[\mathrm{CpRu}\left(\mathrm{NCCH}_{3}\right)_{3}\right]\left[\mathrm{PF}_{6}\right] \mathbf{1 b}$ and bpy was then particularly interesting for the Carroll rearrangement.

It was readily assessed by solubilizing salt $\mathbf{1 b}$ [15] and bpy (1.0 equiv each) in $\mathrm{N}_{2}$-saturated $\mathrm{CH}_{2} \mathrm{Cl}_{2}$ to yield air-sensitive $\left[\mathrm{CpRu}(\mathrm{bpy})\left(\mathrm{NCCH}_{3}\right)\right]\left[\mathrm{PF}_{6}\right]$ 3b (Scheme 2). Subsequent addition of $\left[\mathrm{Bu}_{3} \mathrm{NH}\right][\mathbf{1 1}]$ (1.0 equiv) [23] to the solution of salt $\mathbf{3 b}$ led, as desired, to the formation of zwitterionic adduct 12 [25]. This resulting molecule was readily isolated by column chromatography due to the remarkable elution properties bestowed by $\mathbf{1 1}$ [Fig. 1, $R_{\mathrm{f}} 0.85\left(\mathrm{SiO}_{2}, \mathrm{CH}_{2} \mathrm{Cl}_{2}\right), 76 \%$ ]. As expected, 12 turned out to be completely air- and moisture-stable [26]. With zwitterion $\mathbf{1 2}$ in hands, we turned our attention to its reactivity.

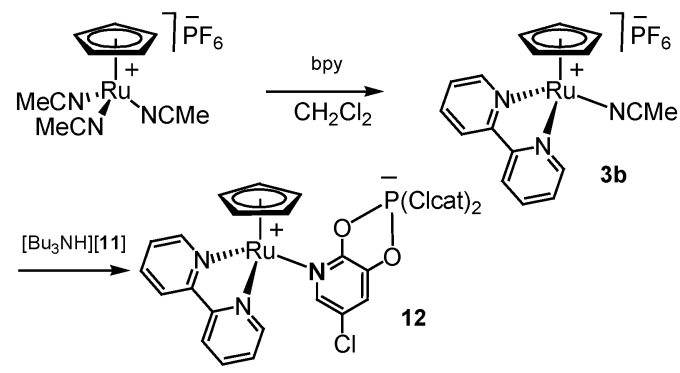

Scheme 2 Synthesis of salt $\mathbf{3 b}$ and zwitterionic complex 12; $\left\{\mathrm{P}(\mathrm{Clcat})_{2}\right\}$ representing the fragment constituted by the hexacoordinated phosphorus atom and the two tetrachlorocatecholate ligands.

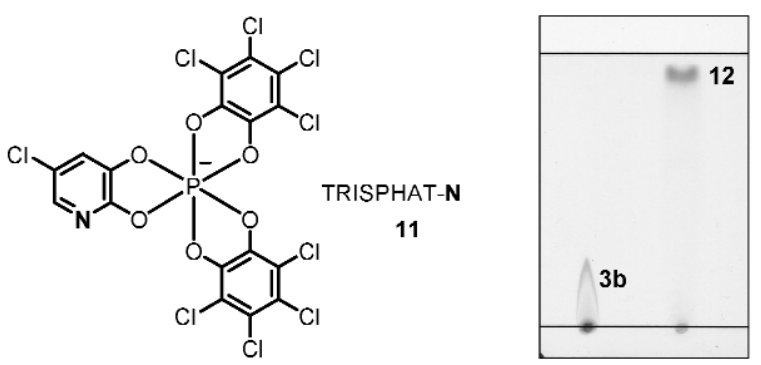

Fig. 1 Hexacoordinated phosphate anion TRISPHAT-N 11 and thin-layer chromatographic behavior $\left(\mathrm{SiO}_{2}\right.$, $\mathrm{CH}_{2} \mathrm{Cl}_{2}$ ) of salt $\mathbf{3 b}$ and lipophilic zwitterionic derivative $\mathbf{1 2}$.

Comparison experiments on the difference in reactivity of complexes $\mathbf{3 b}$ and $\mathbf{1 2}$ in Carroll rearrangement were conducted by the treatment of allylic ester $\mathbf{4 a}$ with catalytic amounts of $\mathbf{3 b}$ or $\mathbf{1 2}$ $(10 \mathrm{~mol} \%)$ in THF at $60{ }^{\circ} \mathrm{C}$. The reactions proceeded smoothly to generate, in both cases, the branched adduct 5a exclusively. Not too surprinsingly, a longer reaction time was necessary with complex $\mathbf{1 2}$ (3b: $100 \%$ conv., 4 h; 12: $100 \%$ conv., 48 h). However, significantly, thin-layer chromatographic monitoring of the reactions revealed that $\mathbf{1 2}$, unlike $\mathbf{3 b}$, was surviving the reaction conditions. Zwitterion $\mathbf{1 2}$ was moreover readily recovered from the crude mixture by column chromatography $\left(\mathrm{SiO}_{2}, \mathrm{CH}_{2} \mathrm{Cl}_{2}\right.$, $85 \%)$. The possibility of reusing the isolated complex as catalyst was tested and subsequent reactions 
occurred indeed without any loss of efficiency or regioselectivity ( 5 consecutive runs performed, b:l > 99:1, 84 to $90 \%$ recovery per run).

The longer reaction time required with complex 12 was, however, of concern. Conditions that would improve the kinetics were looked for. Higher temperatures were considered despite the fact that treatment of $4 \mathbf{a}$ at $140{ }^{\circ} \mathrm{C}$ in a sealed vessel under microwave irradiation yielded the product of rearrangement with a noticeably lower regioselectivity (b:1 4.9:1, Table 3, entry 2), albeit with only $2 \mathrm{~mol} \%$ of $\mathbf{3 b}$ and $60 \mathrm{~min}$ of reaction time. Considering that the lower selectivity was possibly the result of an in situ degradation of $\mathbf{3 b}$ into a less selective entity, the reaction was tested with $\mathbf{1 2}$ [27]. The results are reported in Table 3. To begin, the reactions proceeded with perfect regioselectivity in favor of the branched isomer-in sharp contrast to the reaction with $\mathbf{3 b}$. Relatively short reaction times (30 min) were needed with a catalyst loading of $10 \mathrm{~mol} \%$. Ultimately, catalyst loading could be lowered to 2 mol \% without having an impact on the outcome (95\% conv. b:1 > 99:1, 60 min).

Table 3 Microwave-assisted rearrangement of allylic ester $\mathbf{4 a} .^{\mathrm{a}}$

\begin{tabular}{lccccc}
\hline Entry & {$[\mathrm{Ru}]$} & $\mathrm{x} \mathrm{mol} \%$ & Conv. [\%] & Time [min] & B:1 ratio \\
\hline 1 & - & - & 0 & 120 & - \\
2 & $\mathbf{3 b}$ & 2 & 100 & 60 & $4.9: 1$ \\
3 & $\mathbf{1 2}$ & 10 & 100 & 30 & $>99: 1$ \\
4 & $\mathbf{1 2}$ & 5 & 100 & 30 & $>99: 1$ \\
5 & $\mathbf{1 2}$ & 2 & 90 & 30 & $>99: 1$ \\
6 & $\mathbf{1 2}$ & 2 & 95 & 60 & $>99: 1$ \\
\hline
\end{tabular}

ab or $12(2-10 \mathrm{~mol} \%)$, THF, $140{ }^{\circ} \mathrm{C}, c 0.5 \mathrm{M}$, sealed vessel (microwave irradiation); the results being the average of at least two runs.

The benefit of the increased stability given by anion $\mathbf{1 1}$ became further apparent in the following preliminary study. As just mentioned, an enantioselective variant of this reaction was recently developed using a 1:1 combination of $\left[\mathrm{CpRu}\left(\mathrm{NCCH}_{3}\right)_{3}\right]\left[\mathrm{PF}_{6}\right]$ and enantiopure pyridine imine ligands [28]. Trying to extend the pool of ligands to choose from and determine if a bimetallic catalyst would be beneficial [29], $\left[\mathrm{CpRu}\left(\mathrm{NCCH}_{3}\right)_{3}\right]\left[\mathrm{PF}_{6}\right]$ (2.0 equiv) was treated with tetradentate ligand $N, N^{\prime}$-bis(2-pyridylmethylidene)-1,2-(R,R)-cyclohexanediamine 13 (Scheme 3$)$ derived from commercially available 1,2-(R,R)-cyclohexanediamine and 2-pyridine-carboxaldehyde [30]. ${ }^{1} \mathrm{H}$ NMR monitoring of this experiment indicated the formation of a complex mixture of several $\mathrm{CpRu}$ species including three stereoisomeric bimetallic complexes 14 (Scheme 3), which could not be isolated from the crude. The addition of 2 equiv of $\left[\mathrm{Bu}_{3} \mathrm{NH}\right][\mathbf{1 1}]$ led to the formation of zwitterions $\mathbf{1 5}$ which were isolated by

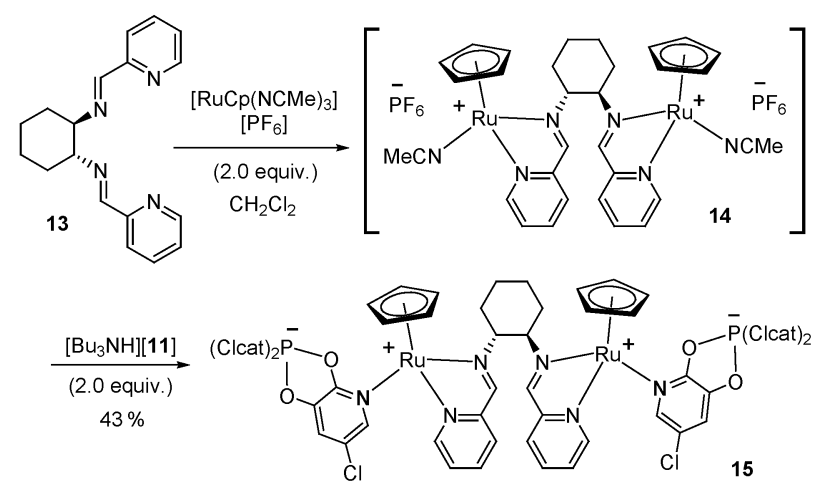

Scheme 3 Synthesis of salt 14 and zwitterionic complex 15. 
chromatography in modest yield $\left(43 \%, \mathrm{SiO}_{2}, \mathrm{CH}_{2} \mathrm{Cl}_{2}\right)[31] .{ }^{1} \mathrm{H}$ and ${ }^{31} \mathrm{P}$ NMR spectroscopy revealed the direct coordination of the anions $\mathbf{1 1}$ onto the Ru metallic centers [23] and confirmed, along with ESI/MS measurements, the formation of the proposed structure $\mathbf{1 5}$ as a complex mixture of stereoisomers [24].

The asymmetric protocol was tested with mixtures of 14 and $\mathbf{1 5}(5 \mathrm{~mol} \%)$ under the classical conditions (THF, $60{ }^{\circ} \mathrm{C}, 0.5 \mathrm{M}, 48 \mathrm{~h}$ ). Compound $4 \mathbf{a}$ reacted to form (+)-5a with, in both cases, excellent regiochemistry (b:1 > 49:1) and good conversion (100 and $85 \%$ ). The enantioselectivity was however very different as ee values of 57 and $85 \%$ were obtained for $\mathbf{1 4}$ and 15, respectively (er 78.5:21.5 and 92.5:7.5). Considering, in the case of 14, that the much lower selectivity might be the result of an in situ degradation of the bimetallic catalysts or of the activity of other species present initially in the mixture [31], care was taken to follow the selectivity as a function of time. Results are reported in Fig. 2. A strong time dependence was observed in the case of 14; the enantioselectivity being much lower at the start of the reaction (ee $18 \%$ after $1 \mathrm{~h}$ ) and reaching essentially the maximal value after $24 \mathrm{~h}$ (ee $56 \%$ ). In the case of the TRISPHAT-N adducts 15, the monitoring revealed an essentially constant selectivity throughout the reaction, indicating, most probably, that the obtained results are due to the bimetallic catalysts and not to other species.

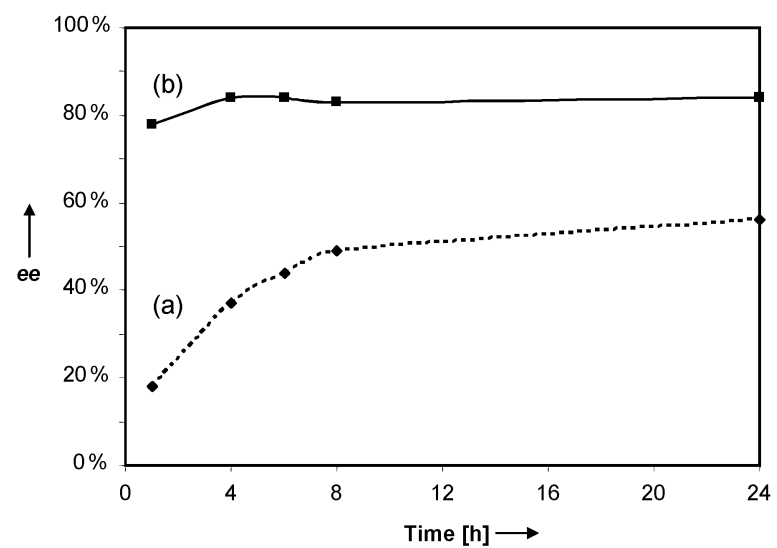

Fig. 2 Enantioselectivity [ee] of $\mathbf{5 a}$ as a function of time [h] in the reactions catalyzed by (a) $\mathbf{1 4}$ (dashed, -- -) and (b) $\mathbf{1 5}$ (plain, —).

In conclusion, our studies have described the first Ru-catalyzed asymmetric Carroll rearrangements using simple-to-make unsymmetrical pyridine-imine ligands and a $\mathrm{Cp}$ rather than a $\mathrm{Cp} *$ source of ruthenium. They have also shown the first synthetic application of an hexacoordinated phosphate anion able to stabilize catalytically active metallic species. The added oxygen and moisture stability that the anion brings allows the isolation and characterization of complexes in regular atmosphere. The important lipophilicity given by the phosphate allows the ready separation of zwitterionic adducts, which in some instances can permit a catalyst reuse after isolation. Furthermore, in the context of the Carroll rearrangement, it is shown that this increased stability improves the regioselectivity of reactions performed under harsh conditions; the enantioselectivity in the case of $\mathbf{1 5}$ (ee $85 \%$ ) being the highest reported so far in an Ru-catalyzed enantioselective Carroll rearrangement. Currently, several other transformations catalyzed by the CpRu moieties are studied and the methodology of stabilization of unstable reactive species is extended to other organometallic complexes. 


\section{REFERENCES AND NOTES}

1. (a) B. M. Trost, D. L. Van Vranken. Chem. Rev. 96, 395 (1996); (b) P. J. Guiry, C. P. Saunders. Adv. Synth. Catal. 346, 497 (2004); (c) S. W. Krska, D. L. Hughes, R. A. Reamer, D. J. Mathre, M. Palucki, N. Yasuda, Y. Sun, B. M. Trost. Pure Appl. Chem. 76, 625 (2004); (d) D. K. Leahy, P. A. Evans. Mod. Rhodium-Catal. Org. React. 191 (2005); (e) H. Miyabe, Y. Takemoto. Synlett 1641 (2005); (f) M. Braun, T. Meier. Angew. Chem., Int. Ed. 45, 6952 (2006); (g) G. Helmchen, A. Dahnz, P. Duebon, M. Schelwies, R. Weihofen. Chem. Commun. 6751 (2007).

2. C. Bruneau, J. L. Renaud, B. Demerseman. Chem.-Eur. J. 12, 5178 (2006).

3. B. M. Trost, P. L. Fraisse, Z. T. Ball. Angew. Chem., Int. Ed. 41, 1059 (2002).

4. (a) M. D. Mbaye, B. Demerseman, J. L. Renaud, L. Toupet, C. Bruneau. Angew. Chem., Int. Ed. 42, 5066 (2003); (b) J. L. Renaud, C. Bruneau, B. Demerseman. Synlett 408 (2003); (c) M. D. Mbaye, B. Demerseman, J. L. Renaud, L. Toupet, C. Bruneau. Adv. Synth. Catal. 346, 835 (2004); (d) M. D. Mbaye, B. Demerseman, J. L. Renaud, C. Bruneau. J. Organomet. Chem. 690, 2149 (2005); (e) B. Demerseman, J. L. Renaud, L. Toupet, C. Hubert, C. Bruneau. Eur. J. Inorg. Chem. 137 (2006).

5. (a) T. Kondo, H. Ono, N. Satake, T.-a. Mitsudo, Y. Watanabe. Organometallics 14, 1945 (1995); (b) T. Kondo, Y. Morisaki, S.-y. Uenoyama, K. Wada, T.-a. Mitsudo. J. Am. Chem. Soc. 121, 8657 (1999); (c) Y. Morisaki, T. Kondo, T. Mitsudo. Organometallics 18, 4742 (1999).

6. (a) H. Kondo, Y. Yamaguchi, H. Nagashima. Chem. Commun. 1075 (2000); (b) H. Kondo, A. Kageyama, Y. Yamaguchi, M.-A. Haga, K. Kirchner, H. Nagashima. Bull. Chem. Soc. Jpn. 74, 1927 (2001); (c) H. Nagashima, H. Kondo, T. Hayashida, Y. Yamaguchi, M. Gondo, S. Masuda, K. Miyazaki, K. Matsubara, K. Kirchner. Coord. Chem. Rev. 245, 177 (2003).

7. (a) R. Hermatschweiler, I. Fernandez, F. Breher, P. S. Pregosin, L. F. Veiros, M. J. Calhorda. Angew. Chem., Int. Ed. 44, 4397 (2005); (b) R. Hermatschweiler, I. Fernandez, P. S. Pregosin, E. J. Watson, A. Albinati, S. Rizzato, L. F. Veiros, M. J. Calhorda. Organometallics 24, 1809 (2005); (c) I. Fernandez, R. Hermatschweiler, F. Breher, P. S. Pregosin, L. F. Veiros, M. J. Calhorda. Angew. Chem., Int. Ed. 45, 6386 (2006); (d) I. Fernandez, R. Hermatschweiler, P. S. Pregosin, A. Albinati, S. Rizzato. Organometallics 25, 323 (2006); (e) I. Fernandez, P. S. Pregosin, A. Albinati, S. Rizzato. Organometallics 25, 4520 (2006); (f) R. Hermatschweiler, I. Fernandez, P. S. Pregosin, F. Breher. Organometallics 25, 1440 (2006).

8. (a) E. C. Burger, J. A. Tunge. Org. Lett. 6, 2603 (2004); (b) E. C. Burger, J. A. Tunge. Chem. Commun. 2835 (2005); (c) C. Wang, J. A. Tunge. Org. Lett. 7, 2137 (2005); (d) J. A. Tunge, E. C. Burger. Eur. J. Org. Chem. 1715 (2005).

9. (a) M. F. Carroll. J. Chem. Soc. 1266 (1940); (b) M. F. Carroll. J. Chem. Soc. 704 (1940); (c) M. F. Carroll. J. Chem. Soc. 507 (1941).

10. (a) M. Defosseux, N. Blanchard, C. Meyer, J. Cossy. Org. Lett. 5, 4037 (2003); (b) M. E. Jung, B. A. Duclos. Tetrahedron Lett. 45, 107 (2004); (c) W. Bonrath, T. Netscher. Appl. Catal., A 280, 55 (2005) and refs. cited therein.

11. For a Pd-catalyzed enantioselective Carroll rearrangement, see: R. Kuwano, N. Ishida, M. Murakami. Chem. Commun. 3951 (2005).

12. For a general review on asymmetric allylic alkylation, see: B. M. Trost. J. Org. Chem. 69, 5813 (2004).

13. For stereoselective procedures with symmetric allylic substrates, see (a) Y. Matsushima, K. Onitsuka, T. Kondo, T. Mitsudo, S. Takahashi. J. Am. Chem. Soc. 123, 10405 (2001); (b) Y. Matsushima, K. Onitsuka, S. Takahashi. Organometallics 24, 2747 (2005).

14. M. D. Mbaye, J. L. Renaud, B. Demerseman, C. Bruneau. Chem. Commun. 1870 (2004).

15. Ligand $\mathbf{8}$ was still unable to accelerate the reaction catalyzed by $\mathbf{1 b}$ under the optimized conditions ( $0 \%$ conv., $7 \mathrm{~d}$, THF, $60{ }^{\circ} \mathrm{C}, 0.5 \mathrm{M}$ ); compound $\mathbf{1 b}$ being prepared using Kündig's protocol: E. P. Kündig, F. R. Monnier. Adv. Synth. Catal. 346, 901 (2004). 
16. The enantiopure primary amines were commercially available or readily prepared following literature precedents. $(R)$-1,2-diphenylethanamine was obtained from the racemate using a semipreparative CSP-HPLC resolution (Chiralpak IA). For the synthesis and absolute configuration assignment, see (a) T. Asai, T. Aoyama, T. Shioiri. Synthesis 811 (1980); (b) M. Cinquini, S. Colonna, F. Cozzi. J. Chem. Soc., Perkin Trans. 1247 (1978); (c) (R)-2,2-dimethyl-1-phenylpropan-1-amine: M. E. Warren, H. E. Smith. J. Am. Chem. Soc. 87, 1757 (1965); (d) V. V. Dunina, M. Y. Kazakova, Y. K. Grishin, O. R. Malyshev, E. I. Kazakova. Russ. Chem. Bull. 46, 1321 (1997).

17. G. Bernardinelli, D. Fernandez, R. Gosmini, P. Meier, A. Ripa, P. Schupfer, B. Treptow, E. P. Kündig. Chirality 12, 529 (2000).

18. The $o-\mathrm{MeO}$ substituent in $\mathbf{9 h}$ creates an $\mathrm{A}(1,3)$ strain situation with the neighboring stereogenic center; the increased rigidity of $\mathbf{9 h}$ vs. $\mathbf{9 g}$ is possibly the reason for the better selectivity. With the $\mathrm{MeO}$ group, $9 \mathrm{~h}$ is also a potential tridentate ligand; the ether linkage functioning possibly as an "on-off"-ligand allowing for the formation of a $\sigma$-allyl Ru-intermediate. We thank a referee for this latter suggestion.

19. (a) K. Soai, S. Yokoyama, T. Hayasaka, K. Ebihara. J. Org. Chem. 53, 4148 (1988); (b) A. Hajra, N. Yoshikai, E. Nakamura. Org. Lett. 8, 4153 (2006).

20. L. Alcaraz, J. J. Harnett, C. Mioskowski, J. P. Martel, T. Legall, D. S. Shin, J. R. Falck. Tetrahedron Lett. 35, 5449 (1994).

21. C. Hubert, J. L. Renaud, B. Demerseman, C. Fischmeister, C. Bruneau. J. Mol. Catal. A: Chem. 237, 161 (2005).

22. S. Constant, S. Tortoioli, J. Müller, D. Linder, F. Buron, J. Lacour. Angew. Chem., Int. Ed. 46, 8979 (2007).

23. S. Constant, R. Frantz, J. Müller, G. Bernardinelli, J. Lacour. Organometallics 26, 2141 (2007).

24. TRISPHAT-N: [bis(tetrachlorobenzenediolato)mono(5-chloropyridine-2,3-diolato) phosphate(V)] anion. This anion $\mathbf{1 1}$ is chiral and was used as a racemate throughout this study.

25. Interestingly, no stable complex is formed by the addition of $\left[\mathrm{Bu}_{3} \mathrm{NH}\right][\mathbf{1 1}]$ to $\left[\mathrm{Cp} * \mathrm{Ru}(\mathrm{bpy})\left(\mathrm{NCCH}_{3}\right)\right]\left[\mathrm{PF}_{6}\right]$.

26. Compound $\mathbf{1 2}$ has been fully characterized using classical spectroscopic and spectrometric means. See the supplementary material.

27. In the absence of $\mathbf{3 b}$ or $\mathbf{1 2}$, allylic ester $\mathbf{4 a}$ is thermally stable at $140{ }^{\circ} \mathrm{C}$ for at least $2 \mathrm{~h}$ with no trace of $\mathbf{1 2}$ or other isomers being observed: see Table 3, entry 1 .

28. S. Constant, S. Tortoioli, J. Müller, J. Lacour. Angew. Chem., Int. Ed. 46, 2082 (2007).

29. Bimetallic complexes can be extremely effective catalysts in a variety of processes, see: (a) B. Coq, F. Figueras. Coord. Chem. Rev. 178-180, 1753 (1998); (b) E. K. Van Den Beuken, B. L. Feringa. Tetrahedron 54, 12985 (1998); (c) M. Shibasaki, N. Yoshikawa. Chem. Rev. 102, 2187 (2002).

30. Compound 13, its enantiomer or the racemate, have been used successfully as ligands in many metal-catalyzed processes, see: (a) T. J. Goodwin, R. S. Vagg, P. A. Williams. J. Proc. R. Soc. N. S. W. 117, 1 (1984); (b) G. C. Van Stein, G. Van Koten, K. Vrieze, C. Brevard, A. L. Spek. J. Am. Chem. Soc. 106, 4486 (1984); (c) P. K. Bowyer, K. A. Porter, A. D. Rae, A. C. Willis, S. B. Wild. Chem. Commun. 1153 (1998); (d) C. R. Baar, L. P. Carbray, M. C. Jennings, R. J. Puddephatt, J. J. Vittal. Organometallics 20, 408 (2001); (e) Y. N. Belokon, M. North, T. D. Churkina, N. S. Ikonnikov, V. I. Maleev. Tetrahedron 57, 2491 (2001); (f) S. Kano, H. Nakano, M. Kojima, N. Baba, K. Nakajima. Inorg. Chim. 349, 6 (2003); (g) M. Klopstra, R. Hage, R. M. Kellogg, B. L. Feringa. Tetrahedron Lett. 44, 4581 (2003); (h) S. Schoumacker, O. Hamelin, J. Pecaut, M. Fontecave. Inorg. Chem. 42, 8110 (2003); (i) Q. T. Nguyen, J. H. Jeong. Polyhedron 25, 1787 (2006); (j) A. Ouali, M. Taillefer, J.-F. Spindler, A. Jutand. Organometallics 26, 65 (2007); (k) J. Song, Q. Shen, F. Xu, X. Lu. Tetrahedron 63, 5148 (2007). 
31. This result reflects the intrinsic instability of ligand $\mathbf{1 3}$ and its complexes $\mathbf{1 4}$. For this reason, recycling of complexes $\mathbf{1 5}$ or reactions under microwave irradiation was not attempted. 